\title{
Spirometric findings among school-aged First Nations children on a reserve: A pilot study
}

\author{
Don D Sin MD MPH'1,2, Heather M Sharpe MN1, Robert L Cowie MD², SF Paul Man MD ${ }^{1}$,
} on behalf of the Alberta Strategy to Help Manage Asthma (ASTHMA) Executive Committee

\begin{abstract}
DD Sin, HM Sharpe, RL Cowie, SFP Man, on behalf of the Alberta Strategy to Help Manage Asthma (ASTHMA) Executive Committee. Spirometric findings among school-aged First Nations children on a reserve: A pilot study. Can Respir J 2004;11(1):45-48.
\end{abstract}

BACKGROUND: Asthma and chronic obstructive pulmonary disease (COPD) are increasing concerns for First Nations peoples in Canada. Although hospital utilization for asthma and COPD among First Nations peoples has been increasing, the prevalence of asthma or wheezing is comparable to national averages.

OBJECTIVES: A pilot study was conducted to determine the prevalence of impaired lung function in school-aged First Nations children. PATIENTS AND METHODS: A First Nations community in northern Alberta was selected to participate. Consent forms and a school health survey were completed by parents or guardians. Children with consent completed spirometry at school, and results were compared with predicted values.

RESULTS: A total of 36 children participated (response rate $70.6 \%$ ). Of these, $19.4 \%$ of parents reported that their child had received a physician diagnosis of asthma at some point in their life; only $28.6 \%$ had a parental report of still having asthma. Parents smoked in $73.1 \%$ of the children's homes. The mean $( \pm \mathrm{SD})$ percentage of forced expiratory volume in $1 \mathrm{~s}\left(\mathrm{FEV}_{1}\right)$ over forced vital capacity (FVC) was $82.6 \% \pm 6.9 \%$ $(94.4 \% \pm 0.08 \%$ of predicted). Evidence of airflow obstruction was found in $25 \%$ of the children. Parental report of the child ever having asthma was associated with impaired lung function ( $\mathrm{OR}$ 3.20; $\mathrm{P}=0.033$ ). Children in a home with reported mold exposure were less likely to have impaired lung function (OR 0.68; $\mathrm{P}=0.030$ ).

CONCLUSIONS: Many children in this study already have established airflow obstruction and may be at increased risk for asthma or COPD. Exposure to mold appeared to be protective. Further research is needed to evaluate the lung health concerns of this population.

Key Words: Airflow obstruction; Asthma; First Nations children

R espiratory problems are common among First Nations chilRdren in Canada (1). For largely unknown reasons, they appear to be at an increased risk of developing lower respiratory tract infections $(2,3)$ and have higher rates of hospitalization for bronchiolitis compared with other children $(4,5)$. The risks of chronic respiratory disorders are also increased among First Nations children. They have rates of emergency visits for asthma and bronchitis that are approximately two times that of
Des découvertes spirométriques chez des enfants d'âge scolaire des Premières nations habitant dans une réserve : Une étude pilote

HISTORIQUE : L'asthme et les maladies pulmonaires obstructives chroniques (MPOC) sont de plus en plus inquiétants dans les populations des Premières nations du Canada. Bien que la consommation de soins hospitaliers augmente au sein des populations des Premières nations en cas d'asthme et de MPOC, la prévalence de l'asthme ou du wheezing est comparable aux moyennes nationales.

OBJECTIFS : Une étude pilote a été menée pour déterminer la prévalence d'altération de la fonction pulmonaire chez les enfants d'âge scolaire des Premières nations.

PATIENTS ET MÉTHODOLOGIE : Une communauté des Premières nations du nord de l'Alberta a été sélectionnée pour participer à l'étude. Les parents et les tuteurs ont rempli des formulaires de consentement et une enquête sur la santé en milieu scolaire. Les enfants consentants ont subi une spirométrie à l'école, et les résultats ont été comparés aux valeurs prédites. RÉSULTATS : Un total de 36 enfants a participé (taux de réponse de 70,6\%). De ce nombre, 19,4\% des parents ont déclaré qu'un médecin avait diagnostiqué de l'asthme chez leur enfant à un moment ou un autre de leur vie, mais que seulement $28,8 \%$ en souffraient encore. Les parents fumaient dans $73,1 \%$ des maisons des enfants. Le pourcentage moyen $( \pm E ́ T)$ du volume expiratoire maximal par seconde (VEMS) par rapport à la capacité vitale forcée $(\mathrm{CVF})$ s'élevait à 82,6 \% $\pm 6,9 \%(94,4 \% \pm 0,08 \%$ des valeurs prévues). On a observé des signes d'obstacles à l'écoulement gazeux chez $25 \%$ des enfants. La déclaration du parent selon laquelle l'enfant avait déjà souffert d'asthme s'associait à une altération de la fonction pulmonaire ( RR $3,20 ; \mathrm{P}=0,033)$. Les enfants qui habitaient dans une maison où l'exposition aux moisissures était évidente étaient moins susceptibles de présenter une altération de la fonction pulmonaire (RR 0,68; $\mathrm{P}=0,030)$.

CONCLUSIONS : De nombreux enfants participant à l'étude présentent des obstacles démontrés à l'écoulement gazeux et sont peut-être plus vulnérables à l'asthme ou à une MPOC. L'exposition aux moisissures semblait protectrice. Des recherches plus approfondies s'imposent pour évaluer les préoccupations en santé pulmonaire de cette population.

${ }^{1}$ Department of Medicine, University of Alberta, Edmonton, Alberta; ${ }^{2}$ James Hogg iCAPTURE Centre for Cardiovascular and Pulmonary Research, Vancouver, British Columbia; ${ }^{3}$ Department of Medicine, University of Calgary, Calgary, Alberta

Correspondence: Dr Don Sin, James Hogg iCAPTURE Centre for Cardiovascular and Pulmonary Research, St Paul's Hospital, Room 368A,

1081 Burrard Street, Vancouver, British Columbia V6A 1Y6. Telephone 604-806-8395, fax 604-806-9274, e-mail dsin@mrl.ubc.ca 
It is not known whether airflow obstruction, a cardinal feature of asthma, is indeed more common in the First Nations community, or whether the increased hospital utilization merely reflects a problem with access to primary care and continuity of care. Because there is a paucity of spirometric data from the First Nations community, we conducted a pilot study among school-aged First Nations children in Alberta to determine the prevalence of impaired lung function in this community.

\section{PATIENTS AND METHODS}

A small, rural First Nations community in northern Alberta was selected to participate in this pilot project. The community chosen was selected because it represented a typical First Nations community in Alberta. It is a relatively remote community and is located on a First Nations reserve (11). Approximately one-half of the residents of this band reside on the reserve and $36.2 \%$ of the population is under the age of 19 years. This community is fairly representative of all First Nations reserves, because provincially, $62.8 \%$ of First Nations reside on a reserve, and $45.6 \%$ of the overall First Nations population are under the age of 19 years (11).

There is only one grade school in this community, and all children from this school were asked to take part in the study. All children from grades one to nine were given a study packet containing an information letter, a consent form and a school health survey for their parents or guardian. A representative of the study later visited the homes of these children to ensure that all parents and guardians had received the packet and to address their concerns. After receipt of informed consent, a trained and certified respiratory therapist performed spirometry using the Spiromate AS-600 (Riko Medical \& Scientific Instrument, USA) on all study participants according to the standards of the American Thoracic Society (12). A prediction equation was used based on values generated from a white population in the United States to determine the expected forced expiratory volume in $1 \mathrm{~s}\left(\mathrm{FEV}_{1}\right)$ and forced vital capacity (FVC) values for the study participants (13). We defined impaired lung function as an $\mathrm{FEV}_{1}$ to FVC ratio below the lower limit of normal based on Hankinson's equation (13). The testing was conducted in the winter months over a threeday period. The child's parent or guardian filled out the survey. Descriptive statistics and SAS software (SPSS Inc, USA) were used to analyze the data. Continuous variables are expressed as mean $\pm \mathrm{SD}$, unless otherwise indicated. Ethical approval was obtained from the University of Alberta Health Research Ethics Board, and support was also given from the regional health authority responsible for the community.

\section{RESULTS}

In total, 36 out of a possible 51 children $(70.6 \%)$ participated in the study. The mean age of the participants was $11.2 \pm 1.9$ years; two-thirds of the cohort were girls. On average, $1.7 \pm 2.7$ days of school were missed due to illness in the month before the survey; $73.1 \%$ of the children lived in a house in which one or more adults smoked. Maternal smoking was observed in $63.9 \%$ of the children's homes, while paternal smoking was present in $61.1 \%$ of the study subjects' homes. In $44.4 \%$ of the cases, other adults living in the same house as
TABLE 1

Clinical characteristics of First Nations children with and without airflow obstruction

\begin{tabular}{lccc}
\hline Variable & $\begin{array}{c}\text { Without airflow } \\
\text { obstruction }\end{array}$ & $\begin{array}{c}\text { With airflow } \\
\text { obstruction }\end{array}$ & P \\
\hline Number & 27 & 9 & - \\
Age (years) (mean \pm SD) & $11.4 \pm 1.9$ & $10.7 \pm 1.9$ & 0.362 \\
Boys (\%) & 33.3 & 33.3 & 1.000 \\
FEV 1 (L) (mean \pm SD) & $2.62 \pm 0.60$ & $2.08 \pm 0.34$ & 0.002 \\
FVC (L) (mean \pm SD) & $3.07 \pm 0.72$ & $2.85 \pm 0.51$ & 0.334 \\
FEV $/$ FVC (\%) (mean \pm SD) & $85.8 \pm 4.3$ & $73.1 \pm 3.9$ & 0.001 \\
Parental report of ever & 11.5 & 44.4 & 0.034 \\
$\quad$ having asthma (\%) & & & \\
Currently wheezy (\%) & 22.2 & 11.1 & 0.431 \\
Parental report of still & 7.7 & 0.0 & 0.161 \\
$\quad$ having asthma (\%) & & & \\
Adult smoker in the house (\%) & 74.1 & 0.0 & 0.006 \\
Mold in the house (\%) & 26.9 & & \\
\hline
\end{tabular}

FEV ${ }_{1}$ Forced expiratory volume in $1 \mathrm{~s}$; FVC Forced vital capacity

the child smoked. The average age of the home in which the children resided was $11.6 \pm 8.3$ years, and $19.4 \%$ stated there was mold in their homes.

The average $\mathrm{FEV}_{1}$ of the study participants was $2.49 \pm 0.59 \mathrm{~L}$ $(97.3 \% \pm 10.9 \%$ of predicted), and the average FVC was $3.01 \pm 0.67 \mathrm{~L}(102.7 \% \pm 10.0 \%$ predicted $)$. The percentage of $\mathrm{FEV}_{1}$ over FVC was $82.6 \% \pm 6.9 \%(94.4 \% \pm 0.08 \%$ of predicted). Of these children, $25 \%$ had spirometric evidence of airflow obstruction (ie, $\mathrm{FEV}_{1}$ to FVC ratio below the lower limit of predicted using Hankinson's equation [13]), and 31\% of children had maximum midexpiratory flows below $80 \%$. Parental reports of asthma were present for $20 \%$ of children, but of these, $71.4 \%$ felt that their children had "outgrown" their asthma. The average age at which the diagnosis of asthma was made was $1.6 \pm 1.5$ years; $19.4 \%$ of the children were reported to be wheezy. On average, children in this study had experienced $2.2 \pm 0.7$ bouts of a "cold" in the previous year.

The clinical characteristics of the cohort - divided according to whether the subjects had impaired lung function - are shown in Table 1. Interestingly, although a majority of parents with children who had a history of asthma felt that their children had "outgrown" their asthma and no longer had symptoms of asthma, parental reports of "ever having asthma" were strongly associated with impaired lung function (OR 3.20; 95\% CI 1.15 to $8.88 ; \mathrm{P}=0.033$ compared with those without a parental report of asthma). On the other hand, children who resided in a house in which molds were reported were less likely to have impaired lung function (OR 0.68; 95\% CI 0.53 to $0.88 ; \mathrm{P}=0.030)$. A significant association was not observed between lung function and other variables, including parental smoking ( $\mathrm{OR} 1.22 ; \mathrm{P}=0.354$ ), daycare use ( $\mathrm{OR} 0.70 ; \mathrm{P}=0.156$ ) or sex (OR 1.00; $\mathrm{P}=1.00)$ (Figure 1).

\section{DISCUSSION}

In the present study, one-quarter of the school-aged First Nations children surveyed had spirometric evidence of airflow obstruction. Indeed, overall, the percentage of $\mathrm{FEV}_{1}$ over FVC was only $82.6 \%$, indicating that many young children in this 
community already had established airflow obstruction, and many more were at an increased risk of developing clinical airflow obstruction in the future. There is growing evidence that once airflow obstruction is established, even with therapy, pulmonary function deficits may not be recoverable (14); as such, these children may be susceptible to chronic obstructive pulmonary disease (COPD) and other chronic pulmonary illnesses.

The reason(s) for the high prevalence of airflow obstruction in this community are largely unknown. Our data, as well as those of others, indicate that a large majority of First Nations children are exposed to secondhand smoke in their homes and their communities. It is well recognized that secondhand smoking by mothers during pregnancy and during early childhood can impair proper development of the pulmonary system, leading to reduced lung function in the child (15). Although we did not observe a significant association between secondhand smoking and impaired lung function (likely due to a small sample size and an extremely high prevalence of parental smoking), secondhand smoke exposure was likely an important contributor to impaired lung function in these children. It is also evident from our data that a prior history of asthma is an important risk factor for airflow obstruction, a finding that is consistent with a prior study (14). Although many asthmatics 'grow out' of their symptoms during late childhood, they may still have impaired lung function, making them more susceptible for future recurrences of asthma or allied conditions such as COPD. Importantly, although First Nations children, as with non-First Nations children, have frequent reports of asthma, they appear to have a lower risk of atopy and allergies (10). Our data also suggest that exposure to molds is 'protective' against the development of airflow obstruction, a finding that is consistent with the 'hygiene hypothesis' (16). It is tempting to speculate that early (and continued) exposure to dusts and molds is responsible for decreased prevalence of allergy among First Nations children (17).

In the study community, only $20 \%$ of the parents reported that their children ever had asthma (compared with 25\% who had spirometric evidence of airflow obstruction), and an even smaller proportion (5.7\% of the cohort) felt that their children still had asthma. These data suggest that asthma is under-recognized and underdiagnosed in the First Nations community. However, a larger study is needed to confirm these early findings. It is noteworthy that parental reports of asthma were highly correlated with airflow obstruction, and were more predictive than questions regarding history of wheezing. This observation may add value to future research conducted using a survey format.

There are several limitations to the present study. First, this study had a relatively small sample size, owing to logistical difficulties in conducting this type of study in geographically remote places. Our data, therefore, cannot be considered definitive, but should provide a stimulus for future (larger) studies. Second, there was poor school attendance by the children, which made it difficult to accurately and efficiently collect the spirometric and survey data. Indeed, we had to make many repeat visits to the school to collect sufficient data for this study. Third, we did not perform spirometry after bronchodilator exposure because of the logistical and technical difficulties of conducting such studies. Thus, we do not know whether the

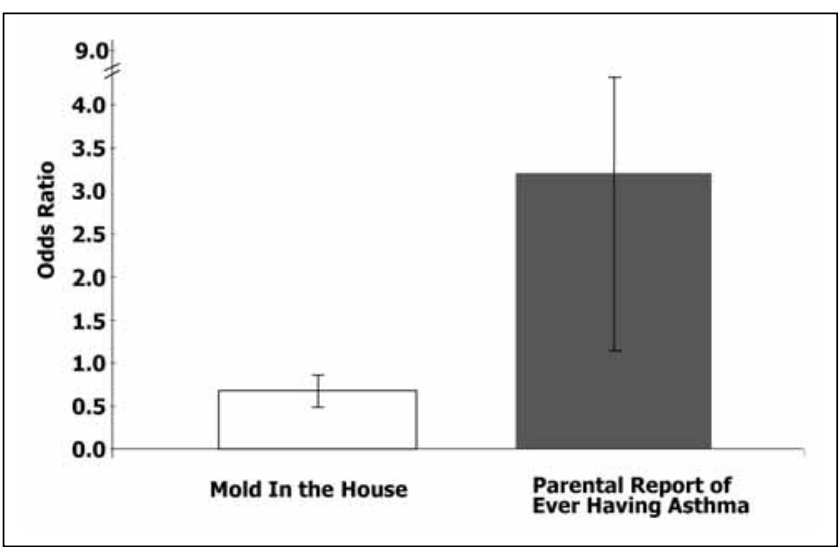

Figure 1) The risk of airflow obstruction among school-aged First Nations children associated with parental reports of mold exposure and of ever having had asthma. The reference group was children without a history of mold in the house or ever having had asthma. Parental reports of the child ever having had asthma were associated with airflow obstruction, while parental reports of mold in the house were associated with protection

airflow obstruction observed among First Nations children was fixed or reversible. Fourth, we could not find good, normative lung function data for the First Nations population. Berman and colleagues (18) reported that Navajo adolescents had lung volumes and flow rates similar to those of their white counterparts. Another comparison of Native American children from Oregon, aged seven to 17 years, reported similar findings (19). Given important differences in the genetic makeup and environmental exposures between the American and Canadian indigenous peoples, it is unclear whether these data can be applied to Canadian First Nations children. Future studies are needed to derive more accurate prediction equations for $\mathrm{FEV}_{1}$ in this population. It would also be instructive for future studies to evaluate bronchial responsiveness and airway inflammation among First Nations children to better understand the physiological mechanism(s) by which these children develop airflow obstruction at such a young age.

\section{CONCLUSIONS}

A segment of the Canadian population - the First Nations people - has received little attention in the lung health literature due to the belief that they have lower rates of respiratory illness. However, it is apparent that this is an area requiring additional research to determine further the extent of airflow obstruction in First Nations children. The present study found that in a small sample of First Nations children, 25\% had objective evidence of airflow obstruction, although only a small proportion of their parents (approximately 5\% of the sample) felt that they still had asthma. Importantly, $73 \%$ of children resided in homes where one or both of their parents smoked. Therefore, interventions aimed at smoking cessation for parents and at preventing First Nations children from initiating smoking would be valuable additions to the public health services in these communities (10). In addition, the impact of exposure to common environmental agents such as mold in the home needs to be explored. Future research with this population is needed to confirm the results of this pilot study. 
THE ASTHMA PROJECT EXECUTIVE COMMITTEE: Dr Paul Man, Project Chair, University of Alberta; Dr Robert Cowie, Co-Chair, University of Calgary; Dr Don Sin, Project Officer, University of Alberta; Ms Heather Sharpe, Research Assistant, University of Alberta; Ms Elaine Andrews, Merck Frosst Canada Ltd; Dr Neil Bell, University of Alberta; Ms Carolyn Nilsson, University of Alberta; Dr Sheldon Spier, University of Calgary; Mr Larry Svenson, Health Surveillance, Alberta Health and Wellness; Dr Luxie Trachsel, Alberta Medical Association; Dr Ross Tsuyuki, University of Alberta

ACKNOWLEDGEMENTS: This study was funded by an unrestricted educational grant from Merck Frosst Canada Ltd. DDS is supported by a New Investigator Award from the Canadian Institutes of Health Research and a Population Health Investigator Award from the Alberta Heritage Foundation for Medical Research. The authors would like to thank Ms Cindy O'Hara for her valuable contributions to this project, and the community, health authority and school for their support and participation in the project.

\section{REFERENCES}

1. Romanow R. A new approach to Aboriginal health. In: Building on Values: The Future of Health Care in Canada. Saskatoon: Commission on the Future of Health Care in Canada, 2002:211-32.

2. Evers S, Orchard J, McCracken E. Lower respiratory disease in Indian and non-Indian infants. Can J Public Health 1985;76:195-8.

3. Harris S, Glazier R, Eng K, McMurray L. Disease patterns among Canadian Aboriginal children. Study in a remote rural setting. Can Fam Physician 1998;44:1869-77.

4. Lowther S, Shay D, Holman R, Clarke M, Kaufman S, Anderson L. Bronchiolitis-associated hospitalizations among American Indian and Alaska Native children. Pediatr Infect Dis J 2000;19:11-7.

5. Houston C, Weiler R, Habbick B. Severity of lung disease in Indian children. CMAJ 1979;120:1116-21.
6. Sin DD, Wells H, Svenson LW, Man SFP. Asthma and COPD in Aboriginals in Alberta, Canada. Chest 2002;121:1841-6.

7. Liu L, Stout J, Sullivan M, Solet D, Shay D, Grossman D. Asthma and bronchiolitis hospitalizations among American Indian children. Arch Pediatr Adolesc Med 2000;154:991-6.

8. Senthilselvan A, Habbick B. Increased asthma hospitalizations among registered Indian children and adults in Saskatchewan, 1970-1989. J Clin Epidemiol 1995;48:1277-83.

9. Stout J, Sullivan M, Liu L, Grossman D. Asthma prevalence among American Indian and Alaska Native children. Pub Health Rep 1999;114:257-61.

10. Hemmelgarn B, Ernst P. Airway function among Inuit primary school children in far northern Quebec. Am J Respir Crit Care Med 1997;156:1870-5.

11. Aboriginal Affairs and Northern Development. First Nations of Alberta: Indian Register Population (December 2000). Edmonton: Research and Development Branch Strategic Services First Nations Affairs, May 2001.

12. Standardization of Spirometry, 1994 Update. American Thoracic Society. Am J Respir Crit Care Med 1995;152:1107-36.

13. Hankinson J, Odencrantz J, Fedan B. Spirometric reference values from a sample of the general US population. Am J Respir Crit Care Med 1999;159:179-87.

14. Gold D, Wypij D, Wang X, et al. Gender- and race-specific effects of asthma and wheeze on level and growth of lung function in children in six US cities. Am J Respir Crit Care Med 1994;149:1198-208.

15. Cunningham J, Dockery D, Gold D, Speizer F. Racial differences in the association between maternal smoking during pregnancy and lung function in children. Am J Respir Crit Care Med 1995; 152:565-9.

16. Strachan DP. Family size, infection and atopy: The first decade of the "hygiene hypothesis". Thorax 2000;55(Suppl 1):S2-10.

17. Douwes J, Pearce N, Heederik D. Does environmental endotoxin exposure prevent asthma? Thorax 2002;57:86-90.

18. Berman S, Arnall A, Cornwall M. Pulmonary function test outcomes in healthy Navajo Native American adolescents. Am J Respir Crit Care Med 1994;150:1150-3.

19. Wall M, Olson D, Bonn B, Creelman T, Buist A. Lung function in North American Indian children: Reference standards for spirometry, maximal expiratory flow volume curves, and peak expiratory flow. Am Rev Respir Dis 1982;125:158-62. 


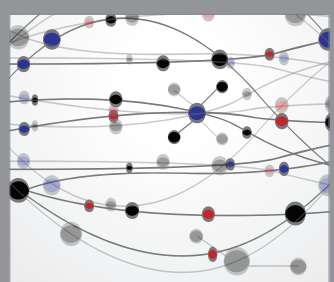

The Scientific World Journal
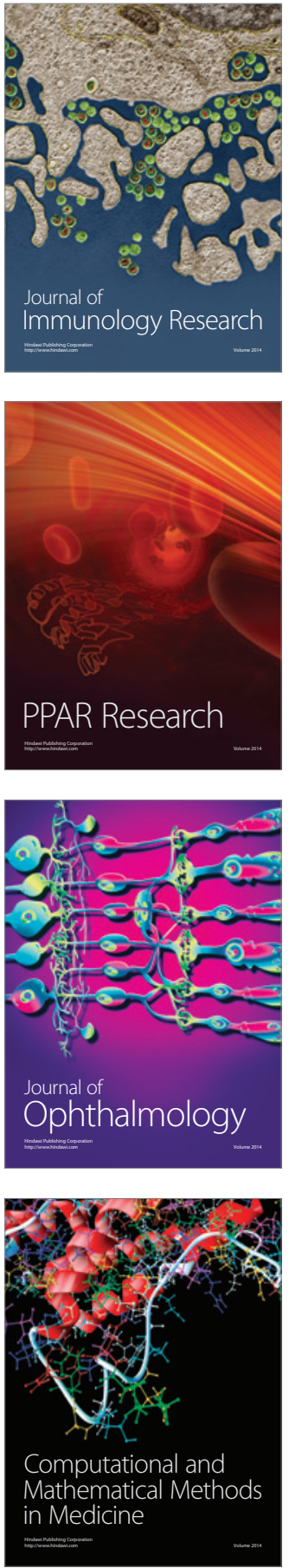

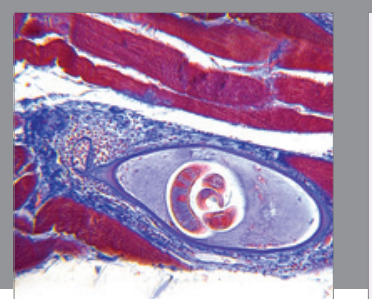

Gastroenterology Research and Practice

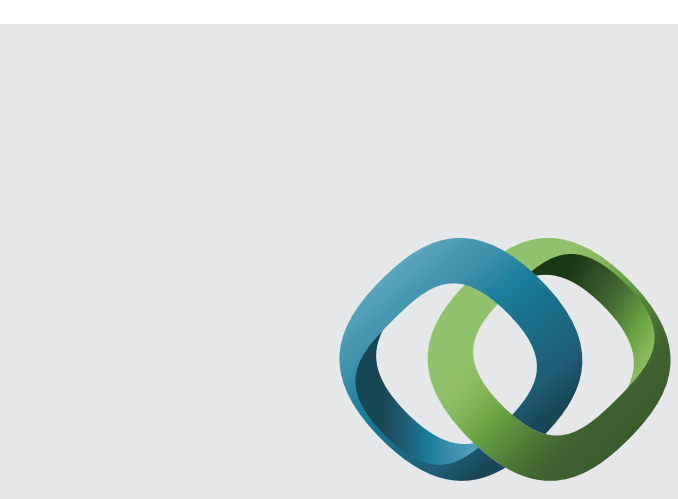

\section{Hindawi}

Submit your manuscripts at

http://www.hindawi.com
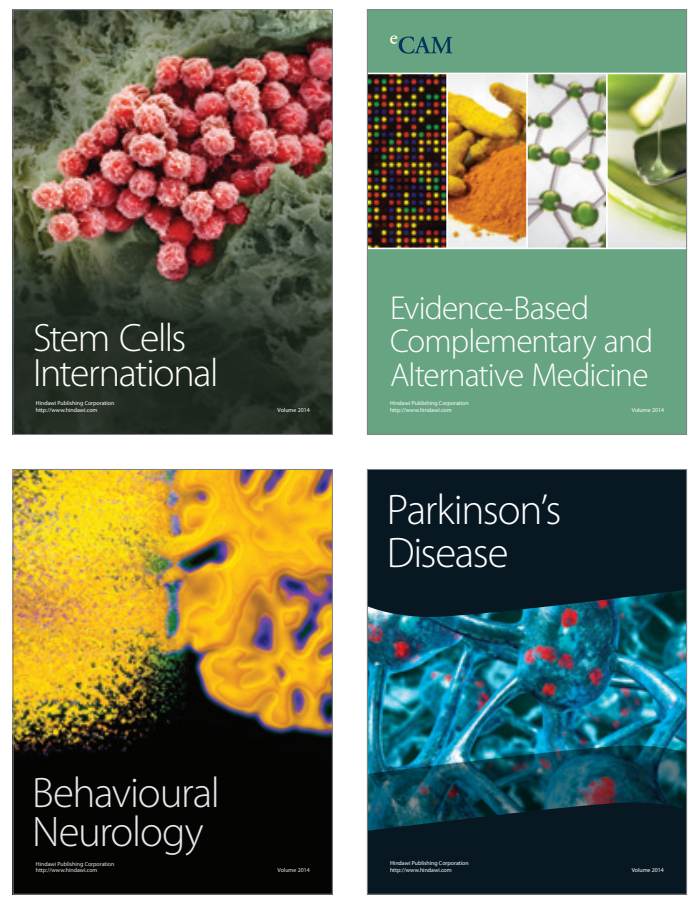
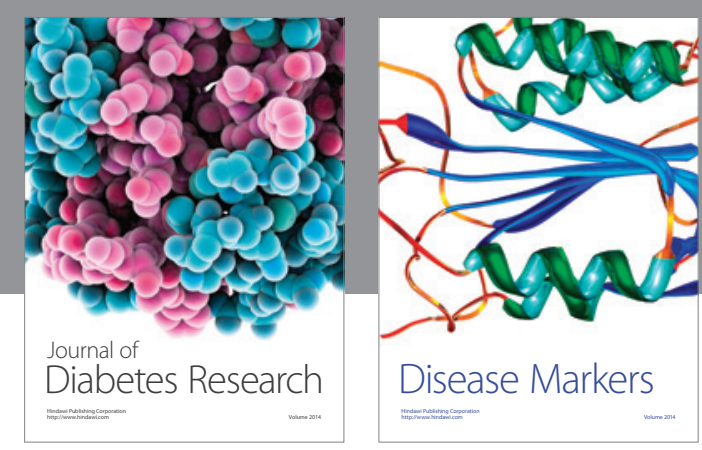

Disease Markers
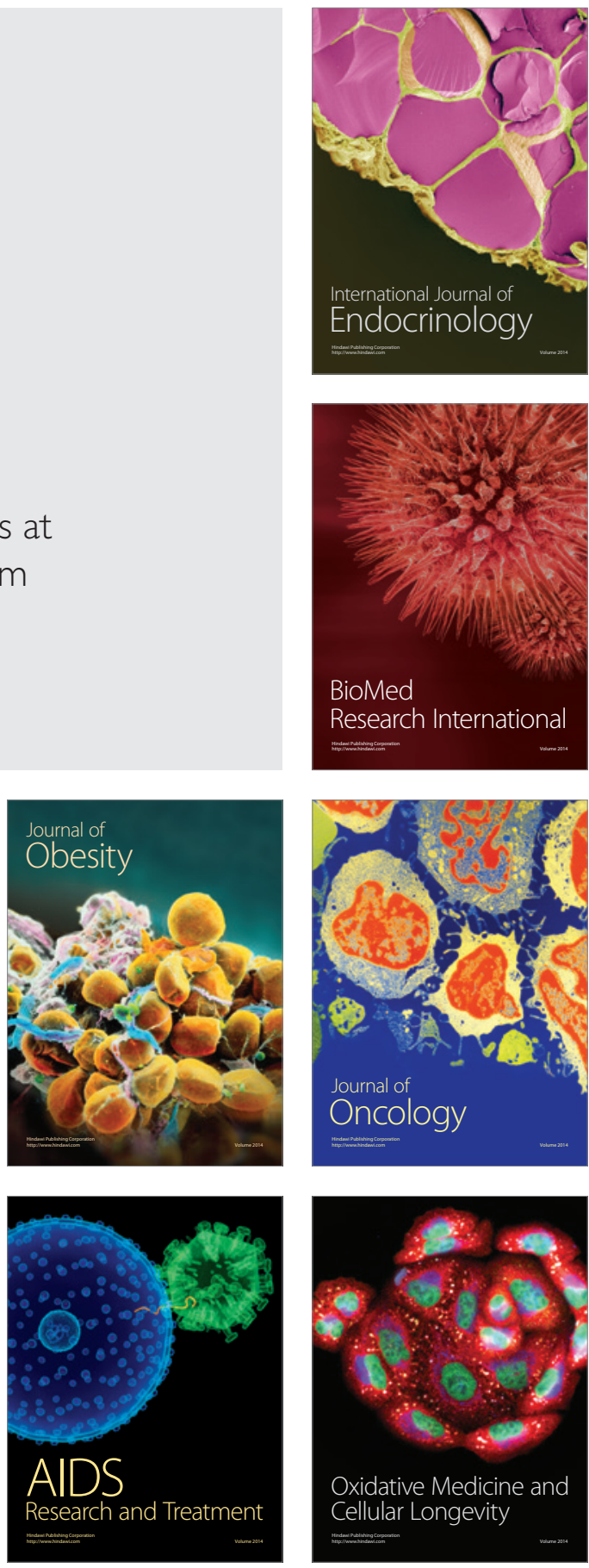